\title{
Physiotherapy for plantar fasciitis: a UK-wide survey of current practice
}

Rob Grieve, $P h D^{1}$, Shea Palmer $P h D^{1}$

${ }^{1}$ Department of Allied Health Professions, Faculty of Health and Applied Sciences,

University of the West of England, Glenside Campus, Blackberry Hill, Bristol, BS16 1DD, United Kingdom

Contact:

Rob.Grieve@uwe.ac.uk

Senior Lecturer in Physiotherapy

Department of Allied Health Professions

Faculty of Health and Life Sciences

Glenside Campus

University of the West of England

Blackberry Hill

Bristol BS16 1DD

Word Count: 2999 - Excluding Abstract or References. 
Objectives: To identify how United Kingdom (UK) physiotherapists currently diagnose, assess and manage plantar fasciitis in routine practice

Design: Online questionnaire survey

Participants: Practising physiotherapists across the UK who treat patients with plantar fasciitis.

Methods: Physiotherapists were approached via 'interactive Chartered Society of Physiotherapy (CSP)' online networks and an email database of clinical educators in South West England. An online questionnaire was developed by reviewing similar existing physiotherapy surveys and consultation with experienced musculoskeletal researchers/clinicians. Descriptive statistics were used to analyse the data.

Results: 285 physiotherapists responded, with 257 complete survey responses. Pain on palpation and early morning pain were the most common diagnostic criteria, with some physiotherapists using no formal test criteria. Advice (237/257,92\%), plantar fasciitis pathology education $(207 / 257,81 \%)$ and general stretching exercises (189/257, 74\%) were most routinely used. Prefabricated orthotics, custom made orthotics and night splints were seldom always used. For the manual therapy approach, the most frequently used modalities were massage, myofascial release, specific soft tissue mobilisations and myofascial trigger point therapy. Less used were electrotherapy, extracorporeal shock wave therapy and needling therapies including cortisone. Commonly used outcome measures were pain assessment, functional tests and range of movement.

Conclusions: An advice and self-management approach was most frequently used. The outcomes of this questionnaire survey may influence the future training and clinical practice of therapists. It may inform and justify the choice of 'usual care' in 
future plantar fasciitis research. Key words: plantar fasciitis, questionnaire survey, physiotherapy, self-management

\section{INTRODUCTION}

Plantar fasciitis (PF) is a common pain condition under the heel of the foot, affecting approximately $10 \%$ of the population during their lifetime. ${ }^{1}$ Histological findings support the thesis that "plantar fasciitis" is in fact a degenerative fasciosis without inflammation. ${ }^{2}$ The condition is therefore often referred to as 'plantar fasciosis' and the term 'plantar heel pain' is also used. This paper will use the most common term 'plantar fasciitis'. The aetiology of PF is multi-factorial with evidence for risk factors such as increased body mass index in a non-athletic population, increased age, reduced ankle dorsiflexion, reduced first metatarsophalangeal joint extension and prolonged standing. ${ }^{3}$ Tightness of the posterior leg muscles (calf and hamstrings) and reduced ankle dorsiflexion have been found in patients with PF. ${ }^{4}$

The Orthopaedic Section of the American Physical Therapy Association (APTA) guidelines ${ }^{5}$ recommended that the following criteria should be used for the diagnosis of heel pain and PF: medial plantar heel pain noticeable with initial steps after inactivity; increased heel pain after increased weight bearing activity; pain on palpation of the proximal insertion of the plantar fascia; limited ankle dorsiflexion range of movement (ROM); abnormal foot posture index score; high $\mathrm{BMI}$ in a nonathletic population; positive windlass test; and negative tarsal tunnel tests.

Differential diagnoses for PF include tarsal tunnel syndrome, entrapment of the first branch of the lateral plantar nerve, radiculopathy, calcaneal stress fracture, and central heel pain syndrome. ${ }^{6}$ 
Various treatment approaches are used for this long-term condition, with different levels of evidence for effectiveness. In a clinical review of PF, ${ }^{7}$ consistent major categories of recommended treatment were identified: biomechanical (including orthotics, footwear modification and taping); stretching techniques (including night splints); extracorporeal shock wave therapy; cortisone (or other) injections; and surgical interventions. Other approaches investigated using randomised controlled trials (RCTs) but with less consistent evidence have included dry needling, ${ }^{8}$ myofascial trigger point therapy ${ }^{9}$ and ankle and midfoot mobilisations. ${ }^{10}$

A previous survey compared physiotherapists' and podiatrists' views on the effectiveness of common PF treatments in order to inform future RCTs. ${ }^{11}$ Of the nine treatments most commonly used, taping was more strongly supported than calf stretching and was recommended for investigation in future RCTs. ${ }^{11}$ Recently a modified version of the Brown ${ }^{11}$ questionnaire survey was administered to compare the perceptions of physiotherapists and podiatrists working in the United Kingdom (UK) National Health Service (NHS) on the management of PF. ${ }^{12}$ Physiotherapists and podiatrists had different perceptions on PF management that may reflect the lack of existing research evidence on treatment effectiveness. ${ }^{12}$ Both professions considered custom foot orthoses to be a podiatrist only role, with more physiotherapists reporting difficulties in addressing foot/ankle biomechanics as a contributing factor compared to podiatrists. ${ }^{12}$

A recent National Institute for Health and Care Excellence (NICE 2015) Clinical Knowledge Summary (CKS) ${ }^{13}$ on the management of PF primarily recommended self-care advice including: education on complete recovery with conservative management within 6 months; rest; shoes with arch support and cushioned heels; 
insoles to correct foot pronation; analgesia or an ice pack for symptom relief; weight loss; and self-physiotherapy in the form of plantar fascia and Achilles tendon stretching.

It is recommended that clinicians use validated self-report questionnaires, such as the Foot Function Index, Foot Health Status Questionnaire, Foot and Ankle Ability Measure or the Lower Extremity Functional Scale before and after interventions intended to alleviate the physical impairments and functional limitations associated with PF. ${ }^{5,14}$ Clinician-administered outcome measures for PF include goniometric ankle dorsiflexion $\mathrm{ROM}^{4}$, algometric pressure pain threshold ${ }^{9}$ and pain scales. ${ }^{10}$

The observations and recommendations described above on diagnosis ${ }^{5,6}$ and outcome measures 4,5, 9,10,14 for PF have been made by an array of health professions and researchers. Reviewing the evidence suggests that there are no standardised methods for diagnosing PF or measuring treatment outcomes. Treatment options for PF are controversial ${ }^{10}$, and to date no evidence focussing specifically on UK physiotherapy practice is available. Due to the conflicting and different level of evidence, it is difficult to ascertain a recommended or preferred method of intervention for this challenging long-term condition. To address these questions a UK wide survey was undertaken to determine how physiotherapists currently assess, diagnose and manage PF. This knowledge will help to underpin future research, education and clinical practice in this area.

\section{METHODS}

\section{Design}

An online questionnaire survey design was used. The project was approved by the 
Faculty of Health and Applied Sciences Ethics Sub-Committee, University of the West of England, Bristol (HLS/13/08/108).

\section{Participants}

Practicing physiotherapists (including private practice and NHS) across the UK, who treated patients with PF, were able to understand and communicate in English and who gave informed consent were included. Physiotherapists were recruited via response to a news item on 'interactive CSP' (iCSP), an online resource for UK physiotherapists provided by the Chartered Society of Physiotherapy (CSP) and via email to clinical educators in the South West of England.

\section{Procedures}

The survey was designed taking into account similar physiotherapy practice questionnaire surveys conducted on other musculoskeletal conditions, namely hip osteoarthritis, ${ }^{15}$ contracted (frozen shoulder), ${ }^{16}$ total hip and knee hip replacement, ${ }^{17}$ and joint hypermobility syndrome in adults. ${ }^{18}$ Existing systematic reviews, relevant PF literature and the expertise of colleagues active in research and clinical practice were used in designing the survey. A draft paper version of the survey, followed by an online version, was distributed to and commented on by five experienced musculoskeletal colleagues including an experienced podiatrist.

Following minor feedback amendments, the questionnaire survey containing 20 questions was finalised. The survey addressed the following main areas: participant characteristics; description of the physiotherapy service; diagnostic criteria; aims of physiotherapy; specific interventions and outcome measures. 
The survey was transposed to the Bristol Online Survey

(http://www.survey.bris.ac.uk/) and was disseminated entirely online. A news item was placed in the iCSP Orthopaedics, Musculoskeletal, Extended Scope Practitioner and Sports \& Exercise Medicine networks. The iCSP news item also contained a link to the Bristol Online Survey on the UWE Faculty of Health and Life Sciences Research Blog, (http://blogs.uwe.ac.uk/teams/hls-research/default.aspx), which included an invitation letter and information sheet. Further to the use of iCSP, physiotherapists on the University of the West of England, Bristol clinical educators' database were e-mailed with study details. Prospective physiotherapy participants known through research interests and continued professional development activities were also identified via email contact lists. Those participants not identified via iCSP, were approached via an email advertisement, containing the same detail as those approached via iCSP. A reminder based on the original advertisement/invitation letter, was sent to the iCSP networks and email contact list after one month.

\section{Data Analysis}

Data was exported into IBM statistics 20 from the Bristol Online Survey and analysed using descriptive statistics, reported as a percentage of valid responses.

\section{RESULTS}

Two hundred and eighty-five physiotherapists responded, with 257 complete survey responses. Only the 257 complete survey responses have been analysed and reported on. The wording of some individual questions and a presentation of the results are in Figures 1-3 and Tables $1 \& 2$. 

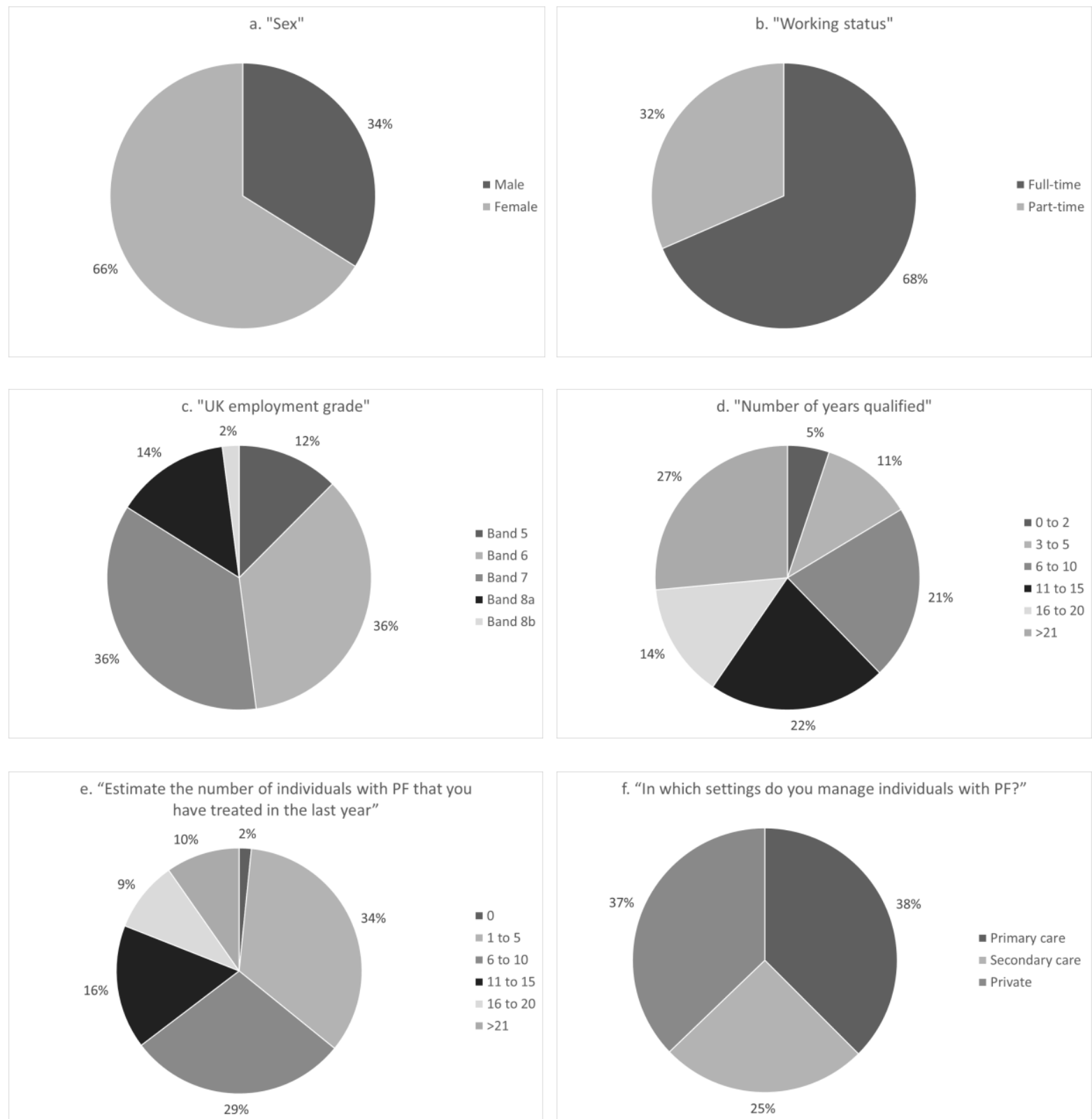

Figure.1. Participant characteristics.

Figures are presented as a \% of valid responses $(n=257)$.

Participants were mainly female and employed full-time, with levels of experience ranging from newly qualified to more than 21 years' clinical experience. There was a relatively even split between those who managed PF in primary care and those in private practice, although some may have worked in both settings and selected both 
options. Within the last year, $(74 / 257,29 \%)$ of participants reported treating 10 or less PF patients.

Most participants received referrals from general practitioners (GPs) and patient selfreferral. The initial assessment was generally 40 or 30 minutes duration, with followup appointments mostly lasted 30 minutes or less. Physiotherapists were split between working as part of a multidisciplinary team or working alone, with the majority referring individuals with PF to a podiatrist (218/257, 85\%). Pain on palpation, early morning pain and pain on plantar fascia stretch were the most commonly used diagnostic criteria/tests. Reduced ankle dorsiflexion, subtalar joint pronation and being overweight were the next most commonly used criteria. Investigations used in diagnosing PF, such as thickened plantar fascia on diagnostic ultrasound and heel spur on X-ray were less commonly used. No formal diagnostic or test criteria for PF was reported by a small number of physiotherapists (20/257, $8 \%)$. 


\begin{tabular}{|c|c|c|}
\hline Question (number of valid responses) & Response Options & $\begin{array}{l}\% \text { of valid } \\
\text { responses }\end{array}$ \\
\hline $\begin{array}{l}\text { "How long (on average) do individuals with PF } \\
\text { wait to see a physiotherapist in your service?" } \\
(n=257)\end{array}$ & $\begin{array}{l}<1 \text { week } \\
1-2 \text { weeks } \\
3-4 \text { weeks } \\
1-2 \text { months } \\
3-4 \text { months } \\
5-6 \text { months } \\
\text { Don't know }\end{array}$ & $\begin{array}{l}27 \\
12 \\
19 \\
29 \\
10 \\
2 \\
2\end{array}$ \\
\hline $\begin{array}{l}\text { "Where do you receive PF referrals from?" } \\
(n=257)^{*}\end{array}$ & $\begin{array}{l}\text { GP } \\
\text { Orthopaedic consultant } \\
\text { Patients (self-referral) } \\
\text { Rheumatology consultant } \\
\text { Podiatrist/Chiropodist } \\
\text { Other }\end{array}$ & $\begin{array}{l}79 \\
48 \\
65 \\
21 \\
34 \\
123\end{array}$ \\
\hline $\begin{array}{l}\text { "On what basis do you offer physiotherapy to } \\
\text { individuals with PF" }(\mathrm{n}=257)^{\star}\end{array}$ & $\begin{array}{l}\text { Individual } \\
\text { Group }\end{array}$ & $\begin{array}{l}100 \\
2\end{array}$ \\
\hline $\begin{array}{l}\text { "What is the duration (on average) of the first } \\
\text { assessment?" }(n=257)\end{array}$ & $\begin{array}{l}10 \text { minutes } \\
20 \text { minutes } \\
30 \text { minutes } \\
40 \text { minutes } \\
50 \text { minutes } \\
60 \text { minutes }\end{array}$ & $\begin{array}{l}1 \\
2 \\
27 \\
39 \\
10 \\
21\end{array}$ \\
\hline $\begin{array}{l}\text { "What is the duration (on average) of each } \\
\text { treatment session?" ( } n=257)\end{array}$ & $\begin{array}{l}10 \text { minutes } \\
20 \text { minutes } \\
30 \text { minutes } \\
40 \text { minutes } \\
50 \text { minutes } \\
60 \text { minutes } \\
\text { Don't know }\end{array}$ & $\begin{array}{l}1 \\
23 \\
68 \\
6 \\
1 \\
1 \\
0\end{array}$ \\
\hline $\begin{array}{l}\text { "How many sessions (on average) do you } \\
\text { offer (including the first assessment)?" } \\
\text { ( } \mathrm{n}=257)\end{array}$ & $\begin{array}{l}1 \\
2 \\
3 \\
4 \\
5 \\
6 \\
>6 \\
\text { Don't know }\end{array}$ & $\begin{array}{l}2 \\
6 \\
11 \\
33 \\
11 \\
19 \\
11 \\
8 \\
\end{array}$ \\
\hline $\begin{array}{l}\text { "Do you work as part of a multidisciplinary } \\
\text { team?" }(n=257)\end{array}$ & $\begin{array}{l}\text { Yes } \\
\text { No }\end{array}$ & $\begin{array}{l}53 \\
47\end{array}$ \\
\hline $\begin{array}{l}\text { "What other health services do you refer } \\
\text { individuals with PF to?" }(n=257)^{\star}\end{array}$ & $\begin{array}{l}\text { Podiatrist } \\
\text { Orthopaedic surgeon } \\
\text { Orthotist } \\
\text { Other }\end{array}$ & $\begin{array}{l}85 \\
39 \\
32 \\
18\end{array}$ \\
\hline $\begin{array}{l}\text { "What diagnostic tests/criteria do you use to } \\
\text { confirm a diagnosis of PF?" }(n=257)^{*}\end{array}$ & $\begin{array}{l}\text { Pain on palpation of medial plantar } \\
\text { heel } \\
\text { Early morning pain } \\
\text { Pain on plantar fascia stretch } \\
\text { Reduced ankle dorsiflexion } \\
\text { Subtalar joint pronation } \\
\text { Overweight } \\
\text { Thickened plantar fascia on } \\
\text { diagnostic ultrasound } \\
\text { Heel spur on X ray } \\
\text { Unable to stand on toes } \\
\text { Pain relief on walking post local } \\
\text { anaesthetic } \\
\text { "Hot Spot" on a bone scan } \\
\text { No formal test/criteria } \\
\text { Other }\end{array}$ & $\begin{array}{l}97 \\
86 \\
83 \\
46 \\
37 \\
27 \\
23 \\
\\
21 \\
19 \\
12 \\
\\
2 \\
8 \\
19\end{array}$ \\
\hline
\end{tabular}


Table 1. Information about clinical services and criteria used to diagnose PF.

*Multiple answers could be selected for these questions therefore total responses may exceed $100 \%$.

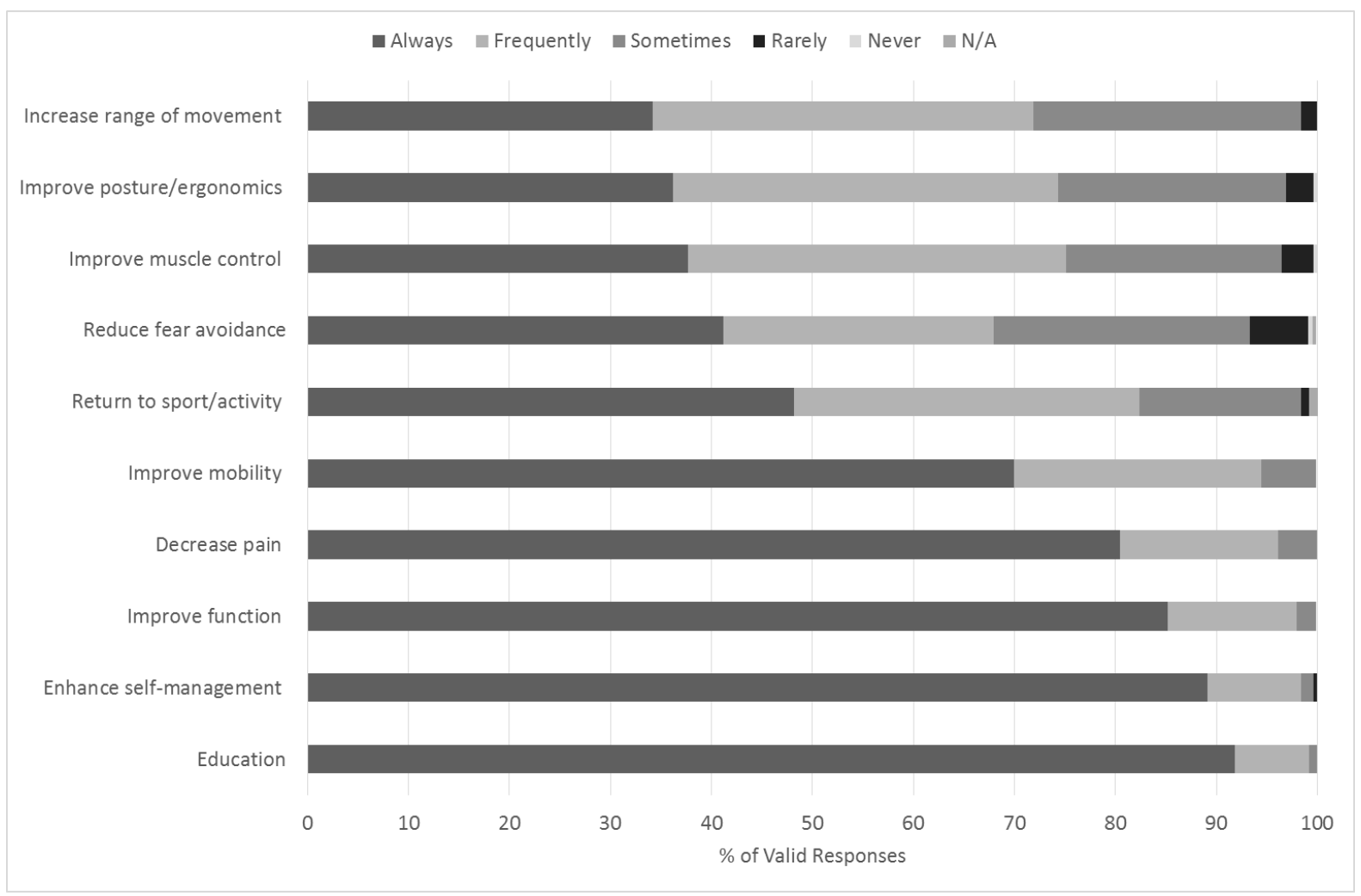

Figure 2. Aims of physiotherapy.

Figures are presented as a \% of valid responses $(n=257)$.

The main aims "always" considered by the majority of physiotherapists in the management of PF in order of preference were education, enhance selfmanagement, improve function and decrease pain. 


\begin{tabular}{|c|c|c|c|c|c|c|}
\hline $\begin{array}{l}\text { "What interventions do you use for PF?" } \\
\text { (number of valid responses) }\end{array}$ & Always & Frequently & Sometimes & Rarely & Never & N/A \\
\hline Advice $(n=257)$ & 92 & 6 & 0 & 1 & 1 & 0 \\
\hline Education on PF pathology $(n=257)$ & 81 & 14 & 3 & 1 & 1 & 0 \\
\hline Self-management $(n=257)$ & 68 & 24 & 6 & 1 & 1 & 0 \\
\hline Exercise (functional) $(n=257)$ ) & 58 & 29 & 11 & 3 & 1 & 0 \\
\hline Exercise (range of movement) $(n=257)$ & 45 & 35 & 16 & 3 & 1 & 0 \\
\hline Exercise (muscle control) $(\mathrm{n}=257)$ & 42 & 31 & 20 & 5 & 2 & 0 \\
\hline Exercise (proprioception) $(\mathrm{n}=257)$ & 38 & 34 & 18 & 7 & 2 & 0 \\
\hline Gait re-education $(n=257)$ & 31 & 35 & 28 & 4 & 2 & 0 \\
\hline Advice (weight loss) ( $\mathrm{n}=257$ ) & 22 & 28 & 38 & 8 & 3 & 0 \\
\hline Stretching $(n=257)$ & 74 & 23 & 4 & 0 & 0 & 0 \\
\hline Calf muscles $(n=257)$ & 69 & 28 & 2 & 1 & 0 & 0 \\
\hline Plantae fascia $(n=257)$ & 66 & 25 & 5 & 4 & 1 & 0 \\
\hline Hamstring muscles $(n=257)$ & 17 & 38 & 30 & 10 & 5 & 0 \\
\hline Strengthening $(n=257)$ & 43 & 33 & 19 & 4 & 2 & 0 \\
\hline Calf muscles $(n=257)$ & 29 & 32 & 26 & 9 & 4 & 0 \\
\hline Intrinsic foot muscles $(n=257)$ & 27 & 35 & 23 & 8 & 7 & 0 \\
\hline Core stability $(n=257)$ & 8 & 27 & 35 & 15 & 14 & 0 \\
\hline Pacing $(n=257)$ & 22 & 34 & 23 & 9 & 11 & 2 \\
\hline \multicolumn{7}{|l|}{ Soft tissue technique } \\
\hline Massage $(n=257)$ & 23 & 32 & 28 & 11 & 8 & 0 \\
\hline Myofascial release $(n=257)$ & 18 & 23 & 27 & 15 & 16 & 2 \\
\hline $\begin{array}{l}\text { Myofascial trigger point therapy } \\
(\mathrm{n}=257)\end{array}$ & 12 & 26 & 30 & 15 & 17 & 1 \\
\hline $\begin{array}{l}\text { Specific soft tissue mobilisations } \\
(\mathrm{n}=257)\end{array}$ & 14 & 28 & 30 & 13 & 15 & 0 \\
\hline Transverse frictions $(n=257)$ & 5 & 16 & 27 & 19 & 33 & 0 \\
\hline Ice $(n=257)$ & 17 & 36 & 27 & 9 & 11 & 1 \\
\hline Ergonomics $(n=257)$ & 16 & 31 & 32 & 11 & 9 & 1 \\
\hline \multicolumn{7}{|l|}{ Joint mobilisations } \\
\hline Ankle joint $(n=257)$ & 5 & 27 & 37 & 21 & 9 & 0 \\
\hline Tibular/fibular joint $(n=257)$ & 4 & 19 & 37 & 26 & 15 & 0 \\
\hline Subtalar joint $(n=257)$ & 5 & 29 & 40 & 15 & 11 & 0 \\
\hline Electrotherapy $(n=257)$ & 5 & 10 & 24 & 22 & 37 & 1 \\
\hline Ultrasound $(n=257)$ & 4 & 14 & 25 & 23 & 34 & 0 \\
\hline Shock wave therapy $(n=257)$ & 2 & 2 & 6 & 4.7 & 65 & 20 \\
\hline Laser $(n=257)$ & 1 & 1 & 5 & 6 & 72 & 14 \\
\hline Orthotics (prefabricated) $(n=257)$ & 4 & 34 & 34 & 14 & 11 & 5 \\
\hline Movement with mobilisation $(n=257)$ & 3 & 16 & 39 & 23 & 19 & 0 \\
\hline Orthotics (custom made) $(n=257)$ & 3 & 24 & 37 & 14 & 13 & 10 \\
\hline Heat $(n=257)$ & 3 & 5 & 19 & 25 & 47 & 2 \\
\hline Hydrotherapy $(n=257)$ & 1 & 2 & 11 & 20 & 60 & 7 \\
\hline Injection (Cortisone) $(n=257)$ & 1 & 4 & 25 & 13 & 38 & 20 \\
\hline Dry needling (257) & 1 & 7 & 19 & 17 & 41 & 16 \\
\hline Night splints $(n=257)$ & 1 & 9 & 19 & 23 & 46 & 3 \\
\hline Injection (Botulinum) ( $\mathrm{n}=257$ ) & 0 & 0 & 2 & 3 & 69 & 26 \\
\hline Acupuncture $(n=257)$ & 0 & 6 & 25 & 23 & 33 & 13 \\
\hline
\end{tabular}


Table 2. Specific interventions used for PF.

Figures are presented as a $\%$ of valid responses. N/A = Not Applicable.

The management approaches most routinely "always" used were advice (237/257,92\%), PF pathology education (207/257,81\%) and general stretching exercises (189/257, 74\%). Stretching included the plantar fascia, calf and hamstring muscles. Prefabricated orthotics, custom made orthotics and night splints were seldom used. The manual therapy approach was used less frequently overall, with the most commonly "always" used modalities being transverse frictions, myofascial trigger point therapy, specific soft tissue mobilisations, myofascial release and massage (range 5-23\%). Less "always" used than manual therapy was electrotherapy $(14 / 257,5 \%)$ including ultrasound, extracorporeal shock wave therapy and laser. Needling therapies were the least used modalities: cortisone, botulinum toxin and dry needling $(<1 \%)$. Please see Table 2 for a more detailed breakdown of the physiotherapy interventions used for PF.

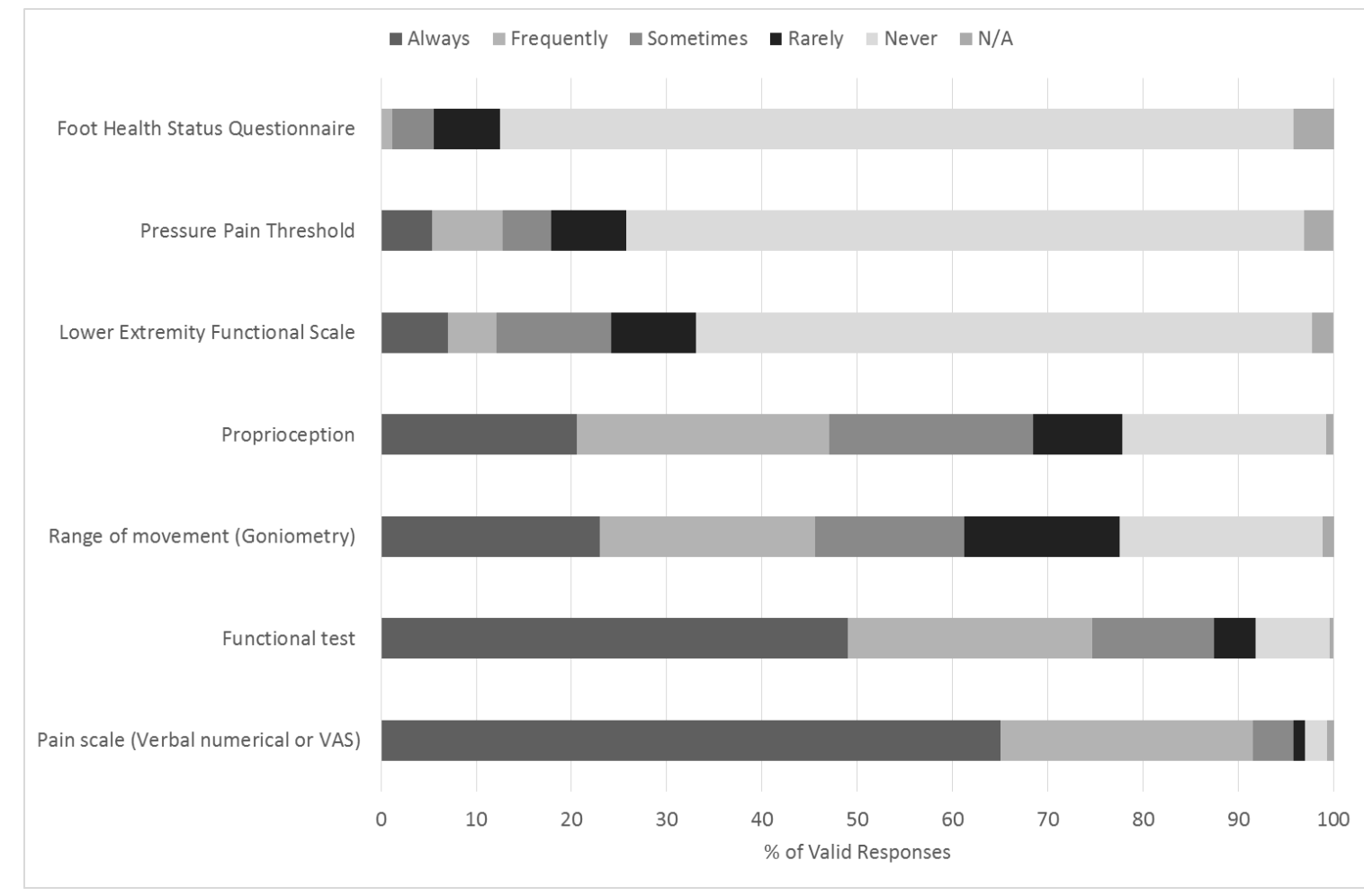


Figure 3. Outcome assessment used for PF.

Figures are presented as a \% of valid responses $(n=257)$.

The most commonly used outcome measures "always" used were pain assessment, functional tests and ROM.

\section{DISCUSSION}

This survey identified a wide range of characteristics and experience amongst the physiotherapy participants. The majority of participants were female which is not quite as high but in line with the Centre for Workforce Intelligence review of the physiotherapy workforce in England ${ }^{19}$ which reported an $84 \%$ female majority. A UKwide Chartered Society of Physiotherapy survey ${ }^{20}$ indicated that musculoskeletal outpatient physiotherapists were most frequently employed at band 6 , followed by bands $7,5,8 \mathrm{a}$ and $8 \mathrm{~b}$. This follows a similar format as those participants employed in the NHS in our survey. The respondents were recruited in a similar split of primary care and private practice and to a lesser extent secondary care physiotherapy practice. We are therefore confident that we have gained insight into a range of usual physiotherapy practice for PF found in both the private and NHS practice settings.

Within the previous year just under a third of the participants reported treating 10 or less PF patients. Given the high reported incidence in the general population and lifetime prevalence of $P F^{21}$ this seems a low number of $P F$ patients treated by survey participants. The highest number of referrals was received from GPs and by self-referral. The proportion of physiotherapists reporting they received referrals from GPs was high, although we were unable to ascertain the delay in GP referral time. 
Delayed GP referral time has been seen as a NHS limitation and a contributing factor by physiotherapists and podiatrists in limiting successful PF treatment outcomes. ${ }^{12}$ The high self-referral rate was proportionally higher than the $46 \%$ of musculoskeletal services available for self-referral across the UK. ${ }^{20}$ Self-referrals for musculoskeletal physiotherapy, compared to traditional medical referral results in significant NHS and patient-related cost benefits. ${ }^{22}$

The majority of physiotherapists treating patients with plantar fasciitis reported that patients waited two months or less for a physiotherapy appointment. This compares favourably with the $71 \%$ of patients seen in 8 weeks or less in musculoskeletal physiotherapy services across the UK. ${ }^{20}$ The majority of physiotherapists offered an initial assessment of 40 minutes or less, with just under half "always" providing follow- up appointments of between four and six sessions on average. These average treatments compare favourably with a UK average number of NHS musculoskeletal physiotherapy sessions of 3.31 and a maximum average of $6 .^{20}$

The three most commonly used diagnostic criteria for PF were pain on palpation of the medial plantar heel, early morning pain and pain on plantar fascia stretch. Apart from a positive windlass test and negative tarsal tunnel tests, physiotherapists appeared to include most of the moderate evidence from the heel pain/PF recommendations of the Orthopaedic Section APTA guidelines. ${ }^{5}$ Further imaging investigations that were used less frequently included heel spur on X-ray, thickened plantar fascia on diagnostic ultrasound and a "hot spot" on a bone scan. Imaging studies are usually not necessary for the diagnosis of PF, ${ }^{14}$ and calcaneal spurs are not a key radiographic feature to distinguish differences between individuals with PF 
and controls. ${ }^{23}$ However, an update on aetiology and diagnosis relating to plantar heel pain indicated that heel spurs, once thought incidental, may have a greater role in causing symptoms than previously thought and that medical imaging has an important role in the diagnosis and understanding of plantar heel pain aetiology. ${ }^{24} \mathrm{~A}$ recent SLR on the use of ultrasound in the assessment of PF, found wide variations in methodology, however results indicated that ultrasound is accurate and reliable for assessing plantar fascia thickness, and for monitoring and guiding therapeutic interventions in patients with PF. ${ }^{25}$

The primary aims of education, enhance self-management, improve function and decrease pain, were reported by over (206/257, $80 \%)$ of physiotherapists as "always" being an aim. All of these primary aims are recommended by NICE for PF. 13

The most commonly reported management interventions that were "always" used of advice, education on PF pathology and general stretching exercises, very closely matched the main aims of physiotherapy that included education and selfmanagement. Stretching included plantar fascia, calf and hamstring exercises. The advice, education and self-management approach was "always" most routinely used, which very closely resembled the aims and scenario management of the recent NICE CKS ${ }^{13}$ recommendations, which advised self-care advice and selfphysiotherapy comprising stretching of the calf and plantar fascia exercises. The NICE CKS ${ }^{13}$ acknowledged a SLR which found insufficient evidence on whether stretching was effective for either pain or function compared to control or other interventions in plantar heel pain. ${ }^{26}$ However, stretching exercises are perceived to 
be an intervention that is of benefit for PF and are recommended clinically. ${ }^{27,} 28$ Stretching was also supported by a recent survey that found that, although physiotherapists and podiatrists had different perceptions on PF management, a key findings was that they both agreed on calf stretching as the most effective treatment for PF. ${ }^{12}$

Compared to the advice, education and self-management approach, manual therapy and therapist-dependent interventions were considerably less "always" used by physiotherapy respondents. For example soft tissue interventions, including transverse frictions and massage, were only "always" used by between 5 and $23 \%$ of respondents. Joint mobilisations for the tibular/fibular and ankle joint were only "always" used by between 4 and 5\%. Recent RCTs have used dry needling ${ }^{8}$, extracorporeal shock wave therapy ${ }^{29}$ and myofascial trigger point therapy ${ }^{9}$, which were infrequently "always" used by physiotherapists (range 1-12\%).

These low response rates for therapist-based interventions are in line with the NICE CKS self-care recommendations ${ }^{12}$ and partially in line with the Orthopaedic Section APTA $2014{ }^{5}$ and Heel Pain Committee of the American College of Foot and Ankle Surgeons guidelines. ${ }^{30}$ The Orthopaedic Section APTA ${ }^{5}$ guidelines found strong evidence for stretching, foot orthoses, night splints, taping and hands on therapist interventions of manual therapy. The American College of Foot and Ankle Surgeons guidelines advocate a plantar heel pain treatment ladder ranging from stretching exercises, orthotics, home physical therapy, cortisone injection through to final 
treatment options, recommended after six months of treatment, involving extracorporeal shock wave therapy and fasciotomy with possible nerve release. ${ }^{30}$

Physiotherapists and podiatrists have different perceptions on PF management, but both agreed in a recent 2014 NHS survey that providing customised foot orthoses is the specialist role of podiatrists. ${ }^{12}$ This may explain why in this online survey only (7/257, 3\%) of physiotherapists "always" provided custom made orthoses. However, the number "frequently" using prefabricated orthoses was (87/257, 34\%). Regardless of the differences in evidence based clinical practice recommendations, orthotic provision is advocated. ${ }^{5,30}$ A previous Cochrane review ${ }^{31}$ indicated that custommade foot orthoses may not reduce foot pain after 3 or 12 months any more than using fake or non-custom foot orthoses.

For outcome measures, a pain scale and functional tests were most often used and reflected the main aims of physiotherapy. It has been recommended that clinicians use validated self-report questionnaires, such as the Foot Function Index, Foot Health Status Questionnaire, Foot and Ankle Ability Measure or the Lower Extremity Functional Scale before and after PF interventions. ${ }^{5,14}$ Only $(13 / 257,5 \%)$ of the respondents "frequently" used the Lower Extremity Functional Scale, with no physiotherapists "always" or "frequently" using the Foot Health Status Questionnaire. Measurement of reduced ankle dorsiflexion ROM, associated with $\mathrm{PF}^{4}$ and a commonly used outcome measure for calf stretching ${ }^{32}$ was only "always" used by $(118 / 257,46 \%)$ of physiotherapists. 
Limitations of the present survey include the exclusion of the Foot Function Index and Foot and Ankle Ability Measure self-report questionnaires as outcome measure options. Due to some of the conflicting evidence and many varied interventions in the literature, it was difficult to fully relate all the intervention findings of this survey to the current evidence. Although the sample size $(n=257)$ did partially focus on NHS clinicians in the SW of England, the use of iCSP would have recruited NHS and private physiotherapy participants from across the UK. Although the results of this survey are only UK specific, they may be transferable and of interest to physical therapists worldwide. Due to the online method, it was impossible to ascertain the exact response rate of this questionnaire survey, which was a further limitation.

\section{CONCLUSION}

This survey successfully captured the views and usual practice of physiotherapists with a wide range of experience, working in a range of practice settings across the UK, representing NHS and private practice. The results of this survey suggest that the aims of physiotherapy and the overall management approach appear to focus on advice and education with an emphasis on self-management. Manual therapy and therapist-dependant modalities such as electrotherapy, extracorporeal shock wave therapy and needling therapies including cortisone advocated for PF were less used. The outcomes of this questionnaire survey may influence the future training and clinical practice of therapists and may inform and justify the choice of 'usual care' in future RCTs for PF. 
Ethical Approval: Ethical approval was granted by The Faculty of Health and Applied Sciences, University of the West of England, Ethics Sub-Committee on the 28th August 2013. The Faculty Ethics Sub-Committee protocol reference number was HLS/13/08/108

Funding: No external funding, this paper was written as part of an internal Early Career Researcher grant from the University of the West of England.

Conflict of Interest: There were no conflicts of interest regarding the collection of data, recording or reporting of this submission.

\section{Acknowledgements}

This research was supported by an internal Early Career Researcher grant from the Faculty of Health \& Applied Sciences, University of the West of England. Bristol. 


\section{REFERENCES}

[1] Uden H, Boesch E KS. Plantar fasciitis - to jab or to support? A systematic review of the current best evidence. J Multidiscip Heal 2011;4:155-64.

[2] Lemont $\mathrm{H}$, Ammirati KM, Usen N. Plantar fasciitis: a degenerative process (fasciosis) without inflammation. J Am Pod Med Assoc 2003;93:234-7.

[3] Irving DB, Cook JL, Menz HB. Factors associated with chronic plantar heel pain: a systematic review. J Sci Med Sport 2006;9:11-22.

[4] Bolívar YA, Munuera P V, Padillo JP. Relationship Between Tightness of the Posterior Muscles of the Lower Limb and Plantar Fasciitis. Foot Ankle Int 2013;34:42-8.

[5] Martin RL, Davenport TE, Reischl SF, McPoil TG, Matheson JW, Wukich DK, et al. Heel pain-plantar fasciitis: revision 2014. J Orthop Sports Phys Ther 2014;44:1-33.

[6] Moore DB. A review of current treatments for plantar fasciitis. US Musculoskelet Rev 2010;70-4.

[7] Orchard J. Plantar fasciitis-Clinical Review. BMJ 2012;345:35-40.

[8] Cotchett MP, Munteanu SE, Landorf KB. Effectiveness of Trigger Point Dry Needling for Plantar Heel Pain: A Randomized Controlled Trial. Phys Ther 2014;94:1083-94.

[9] Renan-Ordine R, Alburquerque-Sendín F, de Souza DPR, Cleland JA, Fernández-de-Las-Peñas $C$. Effectiveness of myofascial trigger point manual therapy combined with a self-stretching protocol for the management of plantar heel pain: a randomized controlled trial. J Orthop Sports Phys Ther 2011;41:43-50.

[10] Shashua A, Flechter S, Avidan L, Ofir D, Melayev A, Kalichman L. The effect of additional ankle and midfoot mobilizations on plantar fasciitis: a randomized controlled trial. J Orthop Sports Phys Ther 2015;45:265-72.

[11] Brown J. Physiotherapists' and podiatrists' views on the effectiveness of treatments for plantar fasciitis. Int J Ther Rehabil 2005;12:151-7.

[12] Ferdinand Nicola, Smith Gordon D, Smith Susan. A survey comparing the perceptions of physiotherapists and podiatrists in the management of plantar fasciitis. Int J Ther Rehabil 2014;21:526-38.

[13] Clinical Knowledge Summary (CKS) [Internet]. National Institute for Health and Care Excellence (NICE 2015). 2015;Available from:

http://cks.nice.org.uk/plantar-fasciitis 
[14] McPoil TG, Martin RL, Cornwall MW, Wukich DK, Irrgang JJ, Godges JJ. Heel pain--plantar fasciitis: clinical practice guildelines linked to the international classification of function, disability, and health from the orthopaedic section of the American Physical Therapy Association. J Orthop Sports Phys Ther 2008;38:1-18.

[15] Cowan SM, Blackburn MS, McMahon K, Bennell KL. Current Australian physiotherapy management of hip osteoarthritis. Physiotherapy 2010;96:289_ 95.

[16] Hanchard NCA, Goodchild L, Thompson J, O'Brien T, Davison D, Richardson C. A questionnaire survey of UK physiotherapists on the diagnosis and management of contracted (frozen) shoulder. Physiotherapy 2011;97:115-25.

[17] Artz N, Dixon S, Wylde V, Beswick A, Blom A, Gooberman-Hill R. Physiotherapy Provision Following Discharge after Total Hip and Total Knee Replacement: A Survey of Current Practice at High-Volume NHS Hospitals in England and Wales. Musculoskeletal Care 2013;11:31-8.

[18] Palmer S, Cramp F, Lewis R, Muhammad S, Clark E. Diagnosis, Management and Assessment of Adults with Joint Hypermobility Syndrome: A UK-Wide Survey of Physiotherapy Practice. Musculoskeletal Care 2015;13:101-11.

[19] Centre for Workforce Intelligence. Physiotherapy workforce review. 2010; Available from:www.cfwi.org.uk.

[20] Chartered Society of Physiotherapy. A survey of NHS Physiotherapy waiting times, workforce and caseloads in the UK 2010-2011. 2011a;Available from: http://www.csp.org.uk/publications/survey-nhs-physiotherapy-waiting-timesworkforce-caseloads-uk.

[21] Rathleff MS, Mølgaard CM, Fredberg U, Kaalund S, Andersen KB, Jensen TT, et al. High-load strength training improves outcome in patients with plantar fasciitis: A randomised controlled trial with 12-month follow-up. Scand J Med Sci Sports 2015;25:292-300.

[22] Chartered Society of Physiotherapy. Musculoskeletal physiotherapy: patient self-referral. 2011b;Available from:http://www.evidence.nhs.uk/qipp.

[23] Osborne HR, Breidahl WH, Allison GT. Critical differences in lateral X-rays with and without a diagnosis of plantar fasciitis. J Sci Med Sport 2006;9:231-7.

[24] Landorf KB, McMillan AM, Menz HB. Plantar heel pain: an update of its aetiology and diagnosis. J Foot Ankle Res 2013;6(S1).

[25] Mohseni-Bandpei MA, Nakhaee M, Mousavi ME, Shakourirad A, Safari MR, Vahab Kashani R. Application of ultrasound in the assessment of plantar fascia in patients with plantar fasciitis: a systematic review. Ultrasound Med Biol 2014;40(8):1737-54. 
[26] Sweeting D, Parish B, Hooper L, Chester R. The effectiveness of manual stretching in the treatment of plantar heel pain: a systematic review. J Foot Ankle Res 2011;4:19

[27] Cutts S, Obi N, Pasapula C, Chan W. Plantar fasciitis. Ann R Coll Surg Engl 2012;94:539-42.

[28] Digiovanni BF, Nawoczenski DA, Malay DP, Graci PA, Williams TT, Wilding GE, et al. Plantar fascia-specific stretching exercise improves outcomes in patients with chronic plantar fasciitis. A prospective clinical trial with two-year follow-up. J Bone Joint Surg Am 2006;88:1775-81.

[29] Gollwitzer H, Diehl P, von Korff A, Schauwecker J, Gerdesmeyer L. A prospective, double blind, randomised trial assessing the effectiveness of a new electromagnetic shock wave device for the treatment of chronic plantar fasciiris. J Bone Jt Surgery 2009;1:S162.

[30] Thomas JL, Christensen JC, Kravitz SR, Mendicino RW, Schuberth JM V, JV, Weil LS Sr, Zlotoff HJ, Bouché R BJ. The diagnosis and treatment of heel pain. a clinical practice guideline-revision. J Foot Ankle Surg 2010;49:S1-19.

[31] Hawke F, Burns J, Radford JA du T V. Custom-made foot orthoses for the treatment of foot pain. Cochrane Database Syst Rev 2008;Available from: http://www.cochrane.org/CD006801/MUSKEL_custom-made-foot-orthoses-forthe-treatment-of-foot-pain.

[32] Radford JA, Burns J, Buchbinder R, Landorf KB, Cook C. Does stretching increase ankle dorsiflexion range of motion? A systematic review. Br J Sports Med 2006;40:870-5. 
